\title{
ИННОВАЦИОННОЕ РАЗВИТИЕ КАК ФАКТОР СТИМУЛИРОВАНИЯ ЭКОНОМИЧЕСКОГО РОСТА: ГОСУДАРСТВЕННОЕ РЕГУЛИРОВАНИЕ В УСЛОВИЯХ ТУРБУЛЕНТНОСТИ ВНЕШНИХ ВОЗДЕЙСТВИЙ
}

\section{INNOVATIVE DEVELOPMENT \\ AS AN INCENTIVE FACTOR ECONOMIC GROWTH: STATE REGULATION \\ IN THE CONDITIONS OF TURBULENCE OF EXTERNAL INFLUENCES}

N. Lebedev

Summary. The article presents an analysis of the specifics of innovative development under the pressure of external turbulence. The interaction of economic growth and innovative development is reflected.

The methodology of consistent implementation of a set of tasks for the development of human capital, the formation of a comfortable living environment and a comprehensive plan for the development of the main infrastructure of the country, etc. is considered.

It is concluded that it is necessary to develop another large and strategically important national project for the revival of the village.

Keywords: economic growth, innovation potential, external influences, national development projects, innovation index, rural development, main infrastructure, demographic situation. $\mathbf{y}$ стойчивость российской экономики понятие многоаспектное, показывает её способность как адаптироваться к внешним влияниям, так и восстанавливаться в условиях турбулентности внешних воздействий, которые в краткосрочном периоде в основном свелись к следующему: во-первых, что серьёзно влияет на экономику - это резкое падение цен на нефть из-за снижения спроса на углеводороды, когда на торгах 21 апреля 2020 г. фьючерсы на июнь упали ниже 20 долл. за баррель; в итоге во второй половине 2020 г. добыча снизилась на 373,5 млн. барр. нефти. Так, в июле 2020 г. экспорт нефти составил 17,22 млн. тонн, что меньше на $25 \%$ по сравнению с предыдущим периодом. Экспорт в страны дальнего зарубежья с января по сентябрь 2020 г. снизился на 27\%; за тот же период имело место сокращение поставок нефти и в СНГ на 37\% [1], чему также способствовали не только нашумевшая пандемия, но и продолжающееся развитие возобновляемой энергетики.

\author{
Лебедев Никита Андреевич \\ Д.э.н., профессор, в.Н.С., ФГБУН «Институт \\ экономики Российской академии наук» \\ ieras@inecon.org
}

Аннотация. Представлен анализ специфики инновационного развития в условиях давления внешней турбулентности. Отражено взаимодействие экономического роста и инновационного развития.

Рассмотрена методология последовательной реализации комплекса задач по развитию человеческого капитала, формированию комфортной среды обитания и комплексного плана развития магистральной инфраструктуры страны и пр.

Сделан вывод о необходимости разработки ещё одного крупного и стратегически важного национального проекта по возрождению села.

Ключевые слова: экономический рост, инновационный потенциал, внешние воздействия, национальные проекты развития, инновационный индекс, развитие сельских территорий, магистральная инфраструктура, демографическая ситуация.
Во-вторых, сокращение объёма поставок товаров отечественного экспорта, который в 2020 г., согласно данным Федеральной таможенной службы, сократился на 20,7\%, (из них в страны дальнего зарубежья - на $85,6 \%$ и 14,4\% - в страны ближнего зарубежья), составив 338,2 млрд. долл. В частности, импорт продовольственных товаров в ценовом выражении в 2020 г. сократился на 1 млрд. долл. (до 29,7 млрд. долл.). В свою очередь, например, экспорт электроэнергии по сравнению с предыдущим годом сократился на $39,6 \%$, также как и экспорт чёрных металлов (40, 11 млн. тонн, минус 1,7\%) [2].

И, в-третьих, ограничил экономическую активность глобальный коронакризис, когда среднегодовой экспорт сократился по отраслевым показателям: реализация товаров машиностроения - на $14 \%$, химической промышленности - на $13 \%$ и т.п. Пессимистический 
Таблица 1. Состав и параметры национальных проектов развития России на период до 2024 года

\begin{tabular}{|c|c|c|c|}
\hline Направление развития & $\begin{array}{l}\text { Национальные } \\
\text { проекты }\end{array}$ & $\begin{array}{l}\text { Количество } \\
\text { федеральных } \\
\text { проектов } \\
\end{array}$ & $\begin{array}{l}\text { Бюджет нац. проекта } \\
\text { (млрд. руб.) }\end{array}$ \\
\hline \multirow{4}{*}{$\begin{array}{l}\text { Человеческий } \\
\text { капитал }\end{array}$} & Здравоохранение & 8 & 1725,8 \\
\hline & Образование & 10 & 784,5 \\
\hline & Демография & 5 & 3105,2 \\
\hline & Культура & 3 & 113,5 \\
\hline \multirow{3}{*}{$\begin{array}{l}\text { Комфортная } \\
\text { среда } \\
\text { обитания }\end{array}$} & $\begin{array}{l}\text { Безопасные и качественные } \\
\text { автомобильные дороги }\end{array}$ & 4 & 4779,7 \\
\hline & Жилье и городская среда & 4 & 1066,2 \\
\hline & Экология & 11 & 4041,0 \\
\hline \multirow{6}{*}{$\begin{array}{l}\text { Экономический } \\
\text { рост }\end{array}$} & Наука & 3 & 636,0 \\
\hline & $\begin{array}{l}\text { Малое и среднее } \\
\text { предпринимательство }\end{array}$ & 5 & 481,5 \\
\hline & Цифровая экономика & 6 & 1634,9 \\
\hline & $\begin{array}{l}\text { Производительность труда } \\
\text { и поддержка занятости }\end{array}$ & 3 & 52,1 \\
\hline & $\begin{array}{l}\text { Международная кооперация } \\
\text { и экспорт }\end{array}$ & 5 & 956,8 \\
\hline & $\begin{array}{l}\text { Комплексный план модернизации } \\
\text { и расширения магистральной } \\
\text { инфраструктуры }\end{array}$ & 11 & 6348,1 \\
\hline
\end{tabular}

Источник: Колин К.К. Национальные проекты В новой стратегии инновационного развития России // sec.chgik.ru/1953-2/

сценарий прогнозирует падение российского ВВП в среднем до $9 \%$ [3].

Несомненно, принимаются меры к смягчению кризисных последствий и для населения, и для малых и средних бизнес-структур, и для денежно-кредитной системы, чему, как нам представляется, несомненно, будет способствовать стимулирование экономического роста посредством использования инновационного потенциала как фактора стимулирования экономического роста в условиях турбулентности внешних воздействий.

Вместе с тем понятно, что Россию ожидает долгий период трудных отношений с коллективным Западом, ей предстоит новая роль ведущей «балансирующей» державы. Но уже сегодня в очередной стратегический прогноз до 2040 года закладываются контуры четырёх сценариев нового мирового порядка [4]. С другой стороны, имеются внутренние ограничения развития, прежде всего, рост демографической нагрузки, технологическая отсталость, возможное снижение мирового спроса на углеводороды [5].

Безусловно, в тентативе выбора оптимальных путей стимулирования экономического роста, преобладающую роль приобретает инновационный потенциал, что рельефно показывают практические результаты осуществления технологичности и инновационности. В данном контексте в докладе «Глобальный инновационный индекс 2020» даётся оценка инновационной деятельности 131 страны; лидерами стали: Свазиленд, Швеция, США, Великобритания. Россия в рейтинге находится на 47-м месте [6].

Преодолеть подобную ситуацию, обеспечив оптимальные пути стимулирования экономического роста, призвано, в том числе и законодательство [7], которое на перспективу фиксирует направления государственного регулирования инновационного развития в рамках национальных проектов развития страны.

С этой точки зрения, курс на последовательную реализацию комплекса задач по развитию человеческого капитала, формированию комфортной среды обитания и комплексного плана развития магистральной инфраструктуры страны и пр. подтверждает необходимость анализа исходя из направлений развития национальных проектов.

Следует отметить, что стратегия инновационного развития страны предусматривает весомые вложения для реализации проектов, развивающих человеческий капитал. Так, на практическое воплощение Нацпроекта «Демография», выделено более 3 трлн. руб. Однако, вызовом становится сокращение населения: в 1992- 
2012 гг. убыль населения составила более 13 млн. чел. [8], в 2020 г.- 352 тыс. чел., а в 2021 г. скорее всего достигнет 290 тыс. чел. За последние пять лет в мирное время население сократилось на 1,2 млн. чел. Растёт сиротство, сокращается продолжительность жизни. Демография, таким образом, стала проблемой комплексного решения [9].

Но, если цель Нацпроекта «Демография», с одной стороны, заключена в необходимости качественного улучшения сложившейся демографической ситуации, то т.н. «устойчивое развитие» навязывает стране сдерживание роста численности населения в пределах 1,6-1,7 ребёнка на одну женщину, когда для воспроизводства необходимо хотя бы 2,5 [10]. К тому же не решив эту серьезнейшую социальную проблему, страна не сможет рассчитывать на экономическое развитие.

Решению демографической проблемы в перспективе может способствовать реализация Нацпроекта «Здравоохранение», с запланированным бюджетом в объёме около 1,7 трлн. руб. Направленность проекта - формирование современных медицинских центров, оказывающих высокотехнологичную медицинскую помощь.

Как показывает анализ, кризис в демографической сфере угрожает развитию человеческого капитала и выход из этого кризиса возможен при комплексном государственном регулировании с целью стимулирования экономического развития.

При этом, впрочем, немаловажным направлением экономического развития выступает существенное улучшение среды общественного обитания.

На решение этой одной из основных социальных задач нацелены три национальных проекта - «Безопасные и качественные автомобильные дороги», «Жилье и городская среда» и «Экология» с суммарным финансированием в 9,9 трлн. руб. (см. табл. 1). Причём, на безопасные и качественные автомобильные дороги и экологию направлено 8820,7 трлн. руб.; на строительство и ремонт жилья, на улучшение городской среды общественного обитания направлена примерно десятая часть этих средств.

В свою очередь, исключительно остро стоит проблема развития сельских территорий, которая включает, в частности, непосредственное водоснабжение жилых комплексов [11], обеспечение сельского населения централизованной канализацией и газоснабжением. Так, в 2019 г. у 66,5\% сельского населения отсутствовала централизованная канализация [12], практически отсутствует горячее водоснабжение.
Учитывая, что программа газификации частных домовладений на 2016-2020 гг. выполнена не была, в текущем году планируется принятие закона о газификации. Если, согласно ныне действующему законодательству [13], подключение к газовым сетям затруднительно и весьма затратно, то ситуацию, возможно, частично изменит новый подход к решению этой проблемы. В июне месяце 2021 г. Государственной Думой ФС РФ будет принят новый закон о газоснабжении, которым предусмотрена газификация домохозяйств до границы их участков без привлечения средств граждан [14].

Тем не менее, следует отметить, что имеются предпосылки социального и экономического развития сельских территорий - утверждена очередная госпрограмма развития сельских территорий [15].

При всём том, по мнению ряда экспертов, «госполитика по отношению к сельскому хозяйству формируется в безальтернативной связке «сельское хозяйство - земли сельхозназначения - сельские жители» и приоритетно направлена на развитие только сельхоздеятельности, без учёта всех возможных форм освоения сельских территорий». Вследствие чего иные формы занятости населения практические не поддерживаются, не субсидируются и условий для их развития не создаются». Как и в городе, имеет место кризис в демографической сфере, который носит комплексный характер, имеет признаки деградации и как считает Б.А. Скупов, угрожает самому существованию деревни [16].

Шаг в правильном направлении - учитывая зарубежный опыт повышать инновационную составляющую не крупных агломераций, а, наоборот, малых хозяйствующих субъектов, расположенных в отдалённых и малонаселённых районах как, например, в Израиле. В агросферу Голландии выделяется 50\% бюджетных средств. В США рост объёмов жилья на селе повышает экономическую активность, улучшает демографические показатели. Инновационные проекты при этом, должны не только учитывать российскую специфику, но и быть экологичными, ресурсообеспеченными.

Далеко не снята с повестки дня и востребованность развития социальной инфраструктуры села (строительство школ, клубов, медицинских пунктов, библиотек, а по аналогии с направлением развития, предусмотренным нацпроектами, безопасных и качественных автомобильных дорог, жилья, формирования сельской среды обитания и т.п.), что привлечёт из городов свежую рабочую силу и поможет преодолеть кризис.

Как мы видим, обобщённый анализ показывает, что усугубившаяся экономическая ситуация, обу- 
словленная в т.ч. западной коллективной санкционной политикой, показывает острую необходимость в ускоренном возрождение села, обновлении сельских территорий, что должно стать дополнительным к имеющимся крупным и стратегически важным национальным проектом, который будет иметь глубокое как социально-экономическое, так и духовно-нравственное содержание.

Ещё одним немаловажным направлением последовательной реализации государственного регулирования инновационного развития в рамках национальных проектов выступает комплексный план модернизации и расширения магистральной инфраструктуры страны. План направлен на развитие транспортных коридоров «Север-Юг» и «Запад-Восток» для пассажироперевозок и транспортировку грузов, что повысит уровень экономической сопряжённости и коммуникаций центров экономического роста посредством расширения и модернизации автодорожной, речной, морской, железнодорожной и авиационной инфраструктуры, к объектам которой причислены автодороги и мосты, железнодорожные вокзалы и морские и речные порты, аэродромы и транспортно-пересадочные узлы, инженерные объекты, линии связи, обеспечивающие строительные работы, реконструкцию и эксплуатацию перечисленных объектов и т.п. [17].

В частности, пассажирский коридор «Центр-Юг» обеспечит сокращение времени движения поездов Москва-Сочи с 32 до 18 часов. Повысится транспортно-железнодорожная доступность к портам Азово-Черноморского бассейна; модернизируются подходы к морским портам Северо-Западного бассейна, Центральный транспортный узел, где будет дополнительно возведено 19 объектов. Транспортная стратегия включает аспект развития внутреннего водного транспорта, и, прежде всего, перенаправление части грузопотоков с автомобильного транспорта на водный, что позволит сбалансировать развитие транспортной системы, повысит конкурентоспособность транспортных услуг, их доступность и качество, для грузоотправителей возрастут социальные функции водного транспорта и т.п. [18].

В рамках строительства транспортного международного коридора «Западный Китай - Европа» инвестируется 705 млрд. руб. в сооружение современной скоростной магистрали Москва-Казань. Наращивать перевозки, поставлять продукцию в страны Азии предполагается по Северному морскому пути (к 2024 году до 80 млн. тонн), использование которого сокращает время перевозок на 10-30\%. На протяжении 5600 км запланировано обустроить и расширить имеющиеся порты. Полным ходом модернизируется инфраструктура РЖД на БАМе и Транссибе - основных артериях, связывающих Россию и страны Азиатско-Тихоокеанского региона, куда будет поставляться, в основном, уголь [19]. Ведётся работа по применению информационных технологий в Арктике, где развивается цифровая логистика и цифровая экономика, что оптимизирует работу морских судов и снижает себестоимость логистики грузоперевозок [20].

Наряду с этим будет продолжено развитие энергетической магистральной инфраструктуры прежде всего в изолированных энергорайонах, проведена модернизация 25\%-ов тепловых электростанций и других генерирующих мощностей всех тепловых структур ЕЭС страны, на что будет направлено только частных инвестиций в объёме около 2,0 трлн. руб. Со своей стороны, естественные монополии инвестируют средства в модернизацию шести магистральных газопроводов, пяти нефтепроводов, в строительство некоторых новых объектов [21].

Представленный анализ отражает специфику инновационного развития в условиях давления внешней турбулентности; сочетание параметров, определённых национальными проектами развития России, должно создать условия для максимального стимулирования экономического роста.

\section{ЛИТЕРАТУРА}

1. Зазуля 0. Бюджет теряет доходы из-за падения спроса на углеводороды // Российская газета — Спецвыпуск № 198 (8252).

2. https://www.finam.ru/analysis/newsitem/tovar-na-prodazhu-chto-proisxodit-s-rossiiyskim-eksportom-20210317-10300/

3. Рогов К. (ред.). Коронакризис — 2020: что будет и что делать? Сценарии развития и меры экономической политики. — Москва: Либеральная миссия.—Вып.9.-М., 2020.-С. 5,11.

4. Дынкин А.А. Международная турбулентность и Россия // Вестник Российской академии наук. - 2020. -Т.90. -№ 3. - C $217-219$.

5. Порфирьев Б.Н., Широв А.А., Узяков М.Н., Гусев М.С., Шокин И.Н. Основные направления социально-экономического развития в $2020-2024$ гг. и на период до 2035 г. // Проблемы прогнозирования. - 2020. -№ 3.—C. 6.

6. Global innovation index 2020.—P.33 // nonews.co/wp-content/uploads/2020/10/gii2020/pdf

7. Указ Президента РФ от 7 мая 2018 № 204 «0 национальных целях и стратегических задачах Российской Федерации на период до 2024 года» (с изм. и доп. от 21 июля 2020 г.) // base.garant.ru/71937200/ 
8. Ионцев В.А., Магомедова А.Г. Демографические аспекты развития человеческого капитала в России и её регионах // Экономика региона. — 2015. № 3.- - .93.

9. https://polit.ru/article/2020/10/22/people/

10. Чернышев Е. Никакими новыми выплатами вымирание России уже не остановить: о чём молчат власти? // www.nakanune.ru/articles/116900/

11. Малышева А.В., Козина Л.Н. 0 проблемах сельского водоснабжения и путях их решения // Вестник НГИЭИ.— 2015. — № 6 (49).—C. $60-67$.

12. Старостина Ю. Росстат назвал долю россиян без доступа к канализации // https://www.rbc.ru/economics/02/04/2019/5ca1d7949a79475d1c2f6e4a

13. Федеральный закон от 31 марта 1999 г. № 69-Ф3 «0 газоснабжении в Российской Федерации» (с посл. изм. и доп. от 26 июля 2019 г.) // base.garant. ru/180285/; Постановление Правительства РФ от 21.07.2008 № 549 (ред. от 19.03.2020) «0 порядке поставки газа для обеспечения коммунальнобытовых нужд граждан» // www.consultant.ru/; Постановление Правительства РФ от 30.12.2013 № 1314 (ред. от 19.03.2020) «06 утверждении Правил подключения объектов к сетям газораспределения» // www.consultant.ru/

14. duma.gov.ru/news/51609/

15. Постановление от 31 марта 2019 г. № 696 «06 утверждении государственной программы Российской Федерации «Комплексное развитие сельских территорий» // www.consultant plus. ru/

16. Скупов Б.А. Без села город не проживёт! Какое будущее у Госпрограммы развития сельских территорий?//ardexpert.ru/article/16506

17. Распоряжение от 30 сентября 2018 года № 2101-р

18. Знатнов С.С. Перспективы инновационного развития речных портов России // Современные научные исследования и инновации. 一 2016. - № 3.

19. Гайва Е. На четыре стороны. Россия создаст сеть международных транспортных коридоров с севера на юг и с запада на восток // Российская газета -Неделя.—№ 278 (8332).

20. Кириллова А.Г.Актуальные аспекты развития международных транспортных коридоров на территории России // Транспорт Российской Федерации. -№ 2 (75).-2018.—C. 54.

21. Постановление № 139-СФ «0б актуальных вопросах развития энергетической инфраструктуры в рамках реализации комплексного плана модернизации и расширения магистральной инфраструктуры на период до 2024 года» // www.consultant.ru/

( ) Лебедев Никита Андреевич ( ieras@inecon.org ).

Журнал «Современная наука: актуальные проблемы теории и практики»

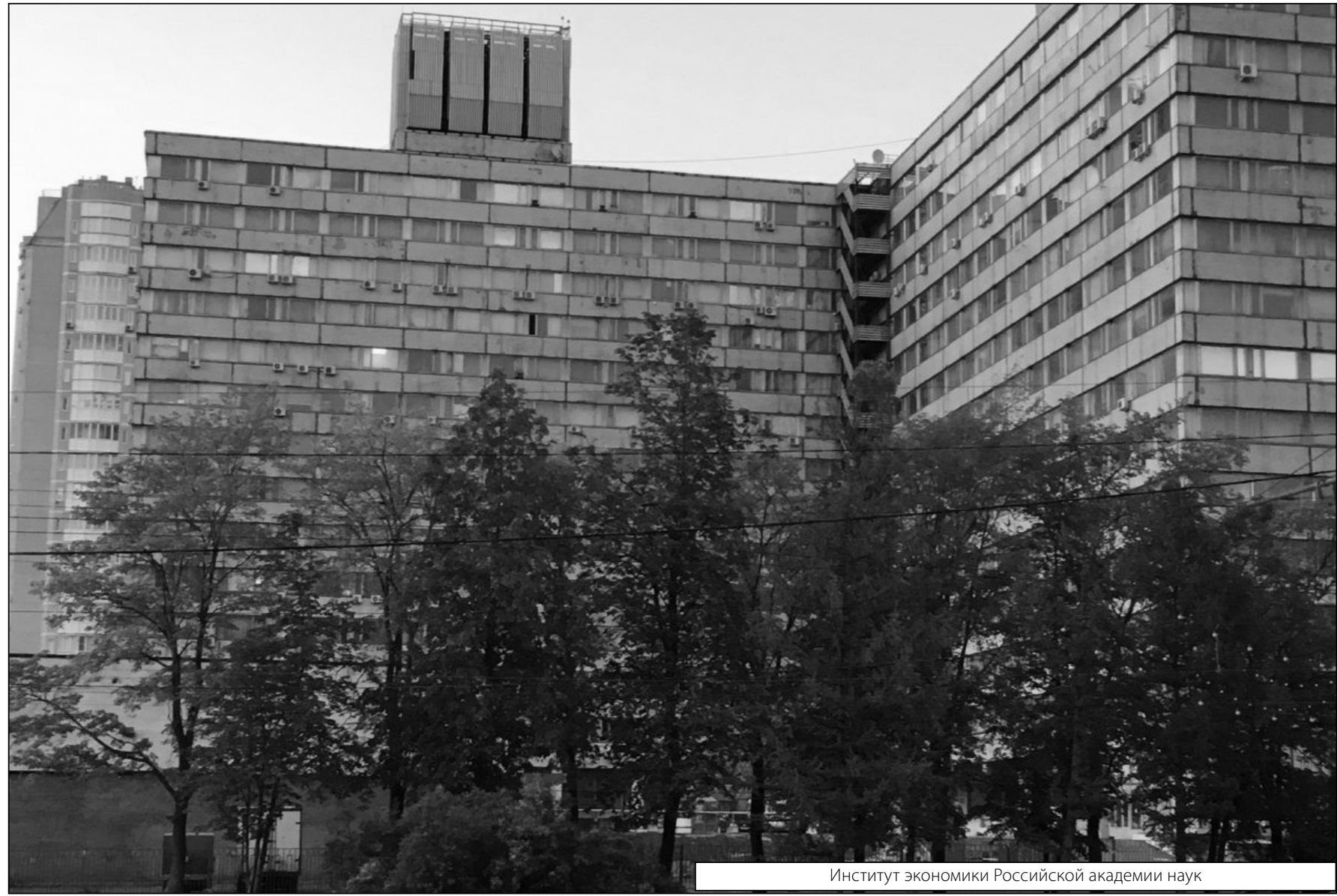

